\title{
Patterns of African Healthcare Funding: Investment Implications for Public-Private Partnerships
}

\author{
Oluwakemi Edet-Utan ${ }^{1 *}$, Gooyabadi $\mathrm{A}^{2}$ \\ ${ }^{1}$ California Department of Correctional Health Care Services (CA, DCHCS), San Diego, \\ USA \\ ${ }^{2}$ California Miramar University, San Diego, USA
}

\begin{abstract}
The coronavirus global pandemic now poses additional peril to the already burdened healthcare systems with inadequate funding in Africa. This paper attempts to present the funding patterns for healthcare in Nigeria, Congo, Tanzania, Egypt, and South Africa. It also explored investor opportunities for lowering OOPs and increasing investor profits. Data were drawn from the WHO, the World Bank, and world charts databases. Government health expenditure was far below what individuals and families pay from out-of-pocket payments (OOPs) for healthcare services except in South Africa, where OOP accounts for only $8 \%$.

Contrary to popular notion, donation funds or foreign aid for healthcare accounts for a lower percentage of total healthcare expenditure in the countries under consideration. Households mostly bore the healthcare expenditure burden (Nigeria's OOPs of 77\%, Congo- 48\%, and Egypt-60\%). Averagely, Nigeria and Congo only spent about 3\% of their national budget on healthcare. In comparison, Tanzania and Egypt spent an average of 4\% and 5\% (South Africa-8\%) between 2010 and 2017, reflecting low-risk protection for households. Specific aspects for investments through publicprivate partnerships (PPP) reviewed in this paper should include designing innovative financing models focusing on risk pooling mechanisms to help bridge the funding gap, local production, and manufacture of pharmaceuticals and healthcare equipment at this time, instead of importation. Investors can, therefore, take advantage of the various initiatives outlined in this paper to achieve better health outcomes in Africa.
\end{abstract}

Keywords: African countries, Donor fund, Healthcare, Investor, Out of Pocket Payments (OOPs), PP.

\section{Introduction}

Achieving quality and sustainable healthcare with improved access to the populations of the world is a huge task. No single organization or government can achieve this enormous task alone. Political and economic changes against the backdrop of unique problems facing different people of different cultures play out when restructuring the healthcare industry. The healthcare industry is no longer viewed as a charitable organization where funds, grants, and donations are made available regularly. Countries are now forced to look inwards based on their uniqueness and find solutions to their related healthcare problems. It has become imperative for global market players to get involved in the African healthcare industry. However, Africa's challenge is that PPP produces extensive results only when on the government's right side [1].

\section{Public-Private Partnership and Healthcare in Africa}

"Public-Private Partnership refers to an agreement between the" government and the private sector, which is "based on a business model that aims to leverage" private sector 
expertise to improve clinical performance in hospitals and other health facilities [2]. A study conducted [2] in Lesotho, Africa, showed that PPP-managed networks delivered more and higher-quality services and achieved significantly different clinical outcomes than that government-managed. It was noted that the changes might be attributed to the changes in management and leadership practices. According to the UNECA report of 2019 [3], to achieve the agenda for Sustainable Development and the African Union, public spending on health needs to become more inclusive. The quality of care of the population in Africa can be improved significantly if all the critical players (governments, donors, investors, and providers, the private sector) can leverage their resources.

Any investor generally needs to understand the characteristics of the business or terrain he desires to invest in. Similarly, investing correctly in healthcare fosters a better foundation for development. With a better outcome, when we consider the long run of investment into countries' healthcare systems, we know that healthy individuals are more productive than unhealthy ones. Healthier workers are competent, and they tend to earn more; they save more, invest more, consume more, and work more extended periods [4]. These healthy individuals contribute immeasurably towards a higher gross domestic product (GDP) [5]. Despite these facts, progress towards achieving the MDGs has been unequal in different regions of Africa, according to WHO. Many other sectors compete with the health sector in terms of the budget at the national level. Besides, healthcare financing has been highly politicized. African countries have limited resources to build and sustain health systems [6].

Egypt (in North Africa) suffers a neglected health care system for over 30 years, characterized by low involvement of government in the public health care system, highly fragmented, with inadequate investment in healthcare, unsafe medical practices, insufficient personnel, and about $72 \%$ of all health care expenditures, are out-of-pocket [7]. Nigeria (West Africa) has a weak and inadequately equipped healthcare infrastructure. Most healthcare funding comes from household/out-of-pocket, with the background of religious, cultural, and socio-economic problems [8]. In the Democratic Republic of Congo (DRC-Central Africa), there is a Mutual Health organizations' presence, a democratically controlled member organization struggling to make people's voices heard from local to the national level, which has mostly produced better health outcomes [9]. In contrast, South Africa's unique healthcare system consists of a broad and overused public sector and an underused and over-resourced smaller private sector. Vambe (2014) [10] reported in his study that South Africa is classified as an upper-middle-income developing country. Still, the health status of South African does not reflect the economic advancement of this country [11].

In the last two decades, Tanzania's national government plays a significant role in the healthcare system's major funder with some support from tax-based collections and implementing the Community Health Fund (CHF) program [12]. Donor funding has also significantly declined in Tanzania [13]. East Africa is characterized by weak and inadequate funding for medical products. Thus, there is ineffective regulation of medical products.

It is now imperative for African governments to increase their commitment to better health outcomes for their citizens. When investors understand the layers of the African healthcare systemic problems, it gives them a better insight into developing the right strategy to foster better healthcare outcomes. Five countries have been selected per each African region to reflect the wide gaps in cultural differences, varying problems faced by these countries and describe their healthcare systems in the light of PPPs and restructure in the healthcare sector that can foster improved healthcare outcomes. The goal of this paper is to present the funding patterns for healthcare in Africa and explore investors' 
opportunities that focus on lowering OOPs and increasing investor profits to achieve better health outcomes for its population, focusing on five selected countries in Africa (Nigeria, Tanzania, Congo, South Africa, and Egypt).

\section{Healthcare Business in Africa/Donor Activities in Africa}

Transforming domestic investments in health into actual progress to achieve Universal Health Coverage in Africa is challenging [14]. Donorfunded projects in Africa are frequently not channeled through already existing government structures in the healthcare system. The entities that bring the fund often collaborate with nonstate development actors such as NGOs to prevent aid capture, improve the program's effectiveness, and ensure increased effective health service delivery [15]. While some argue that funding partners' allocation and management of their funds locally in implementing healthcare programs may be beneficial in terms of project implementation, the central role of the ministry of health in sustaining the project or program has been bypassed as this might counteract alignment, harmonization, ownership and finally, sustainability. Thus, exploring existing and emergent public, Private Partnerships is very appropriate at this time.

\section{Materials and Methods}

\section{Study Design}

This descriptive study employs time-series data to describe the African Healthcare funding streams, focusing on five regions and identifying one country per region to be studied in-depth for this paper. Several author's existing data, with significant data drawn from the WHO, the World Bank, and world charts, were also utilized.

\section{Location and Method of Country Selection}

Africa has five regions: North, West, Central, East, and South Africa. Each country was randomly selected based on the centrality of the country to that region in Africa: North Africa Egypt; West Africa - Nigeria; Central Africa the Democratic Republic of the Congo; East Africa - Tanzania; and South Africa - South Africa.

\section{Method of Data Collection}

This study's raw data and charts were obtained from the WHO Global Expenditure Database from 2000 to 2017 [16]. There was no data available for Tanzania by WHO, but data was obtained from various authors cited in this paper. Specific focus on GGHED - Gross Government Health Expenditure, EXT External Sources including donor funds, OOPS - Out-of-Pocket Payments, and other sources of funding healthcare in Africa insurance, loans, donations, missions, and the likes. Some figures were also extracted from the United Nations Economic Commission for Africa (UNECA) [3] report of 2018. Data were also extracted from macrotrends.com regarding spending on healthcare per capita and GDP in Nigeria, Congo, Egypt, Tanzania, and South Africa.

\section{Method of Data Analysis}

Finally, the author attempted to synthesize facts from the various literature to explore and identify possible aspects of healthcare investments against these problems' backdrop in the African healthcare industry. Data were arranged in simple tables and presented in charts.

\section{Findings and Results}

\section{Funding Patterns for Healthcare in Africa}

In Africa, out-of-pocket expenditure accounts for about $36 \%$ of Africa's total healthcare spending, leading to a $\$ 66 \mathrm{bn}$ per annum financial gap. Averagely, the African government spends about $7.2 \%$ of its budget on healthcare between 2000 and 2015 though with wide variations across regions [3]. 


\section{The Trend and Sources of Funding}

As presented in figures 1 to 4, Nigeria, Congo, Egypt, and South Africa all have a mix of funding sources for healthcare service provision in each country. However, it follows a similar trend in funding from each source, except for South Africa. According to the WHO database 2017, Nigeria has the highest level of out-of-pocket payments for up to $77 \%$ of all healthcare spending, with only $14 \%$ total government expenses. On the other hand, out-of- pocket expenses in Congo and Egypt accounted for $48 \%$ and $60 \%$ in 2017, respectively. Regarding external funding sources, including donations and foreign aid, $8 \%$ of healthcare expenses in Nigeria and Congo were from external funding sources. Of the four countries being considered, South African government expenditure on healthcare accounted for about $54 \%$, with $37 \%$ from other sources reducing outof-pocket payments to just $8 \%$. WHO did not report Tanzania's healthcare expenditure data during this period.

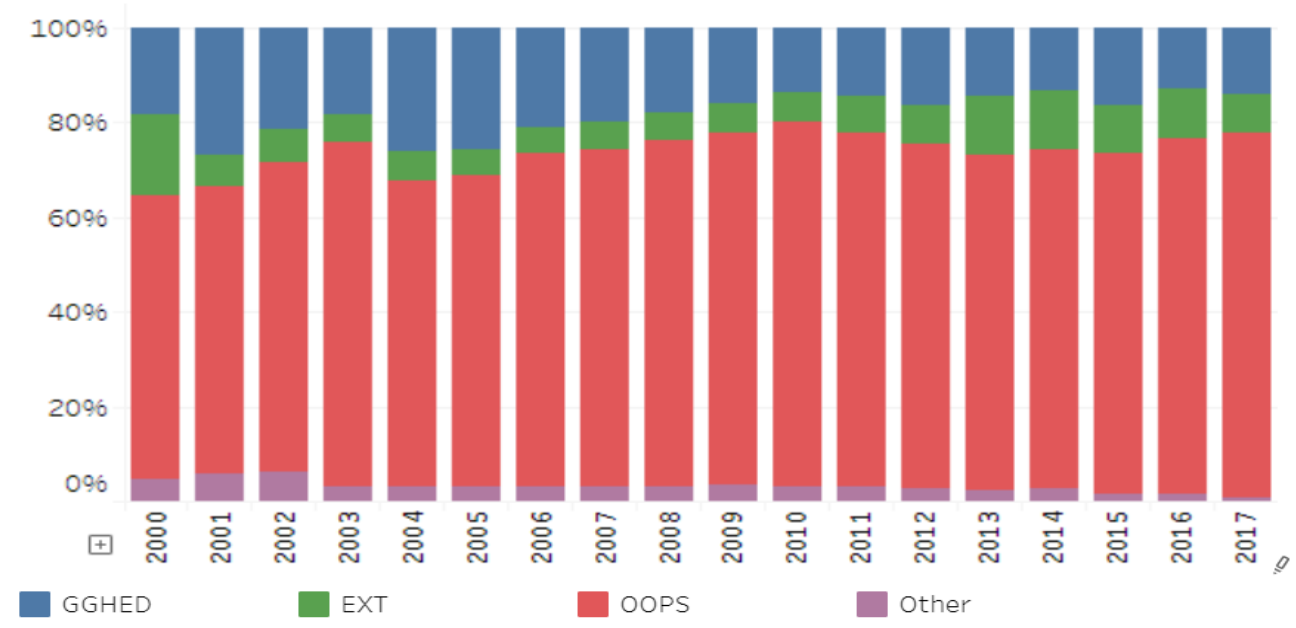

Figure 1. Nigeria's Sources of Health care Financing (Charts and Data Source: WHO Global Expenditure Database, 2000-2017)

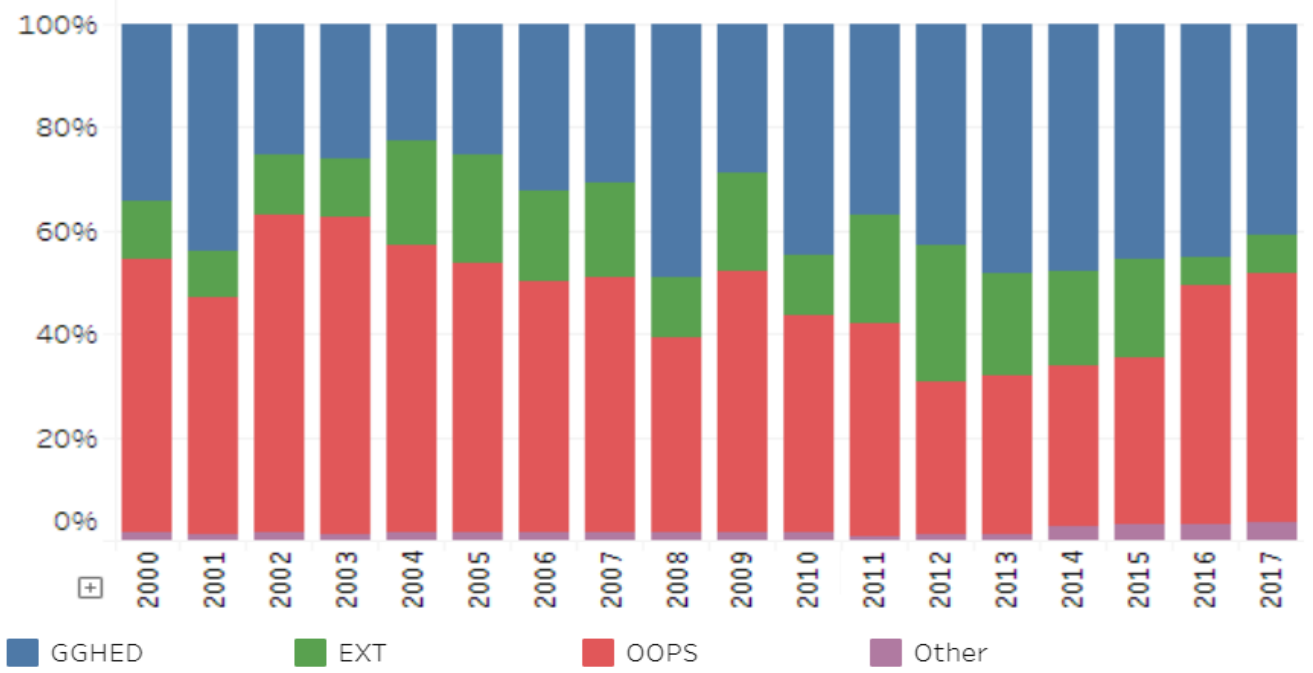

Figure 2. Congo's Sources of Health care Financing 


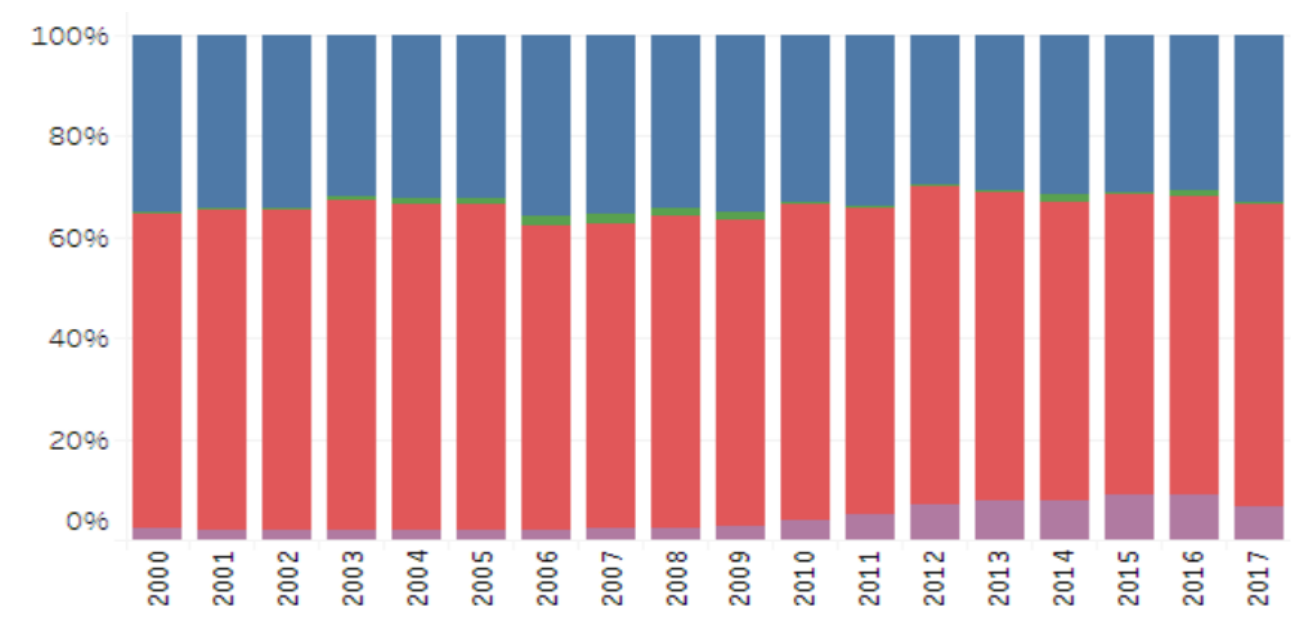

GGHED

EXT

OOPS

other

Figure 3. Egypt's Sources of Health Care Financing

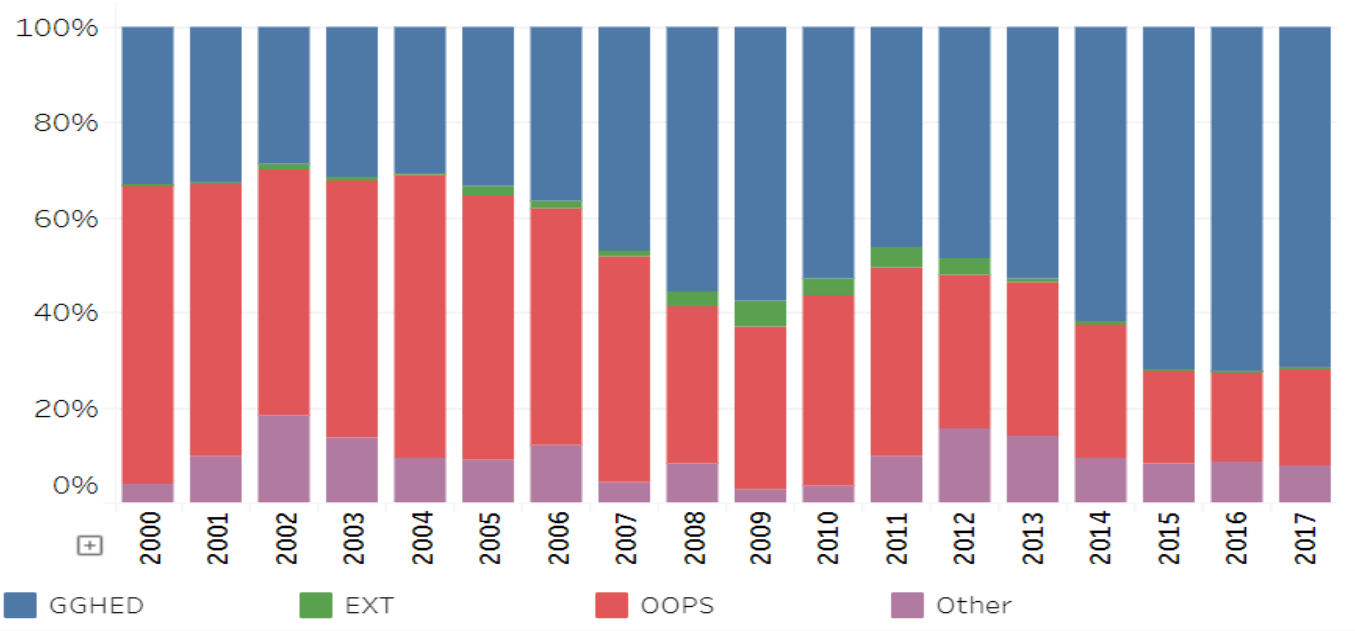

Figure 4. South Africa's Sources of Health care Financing

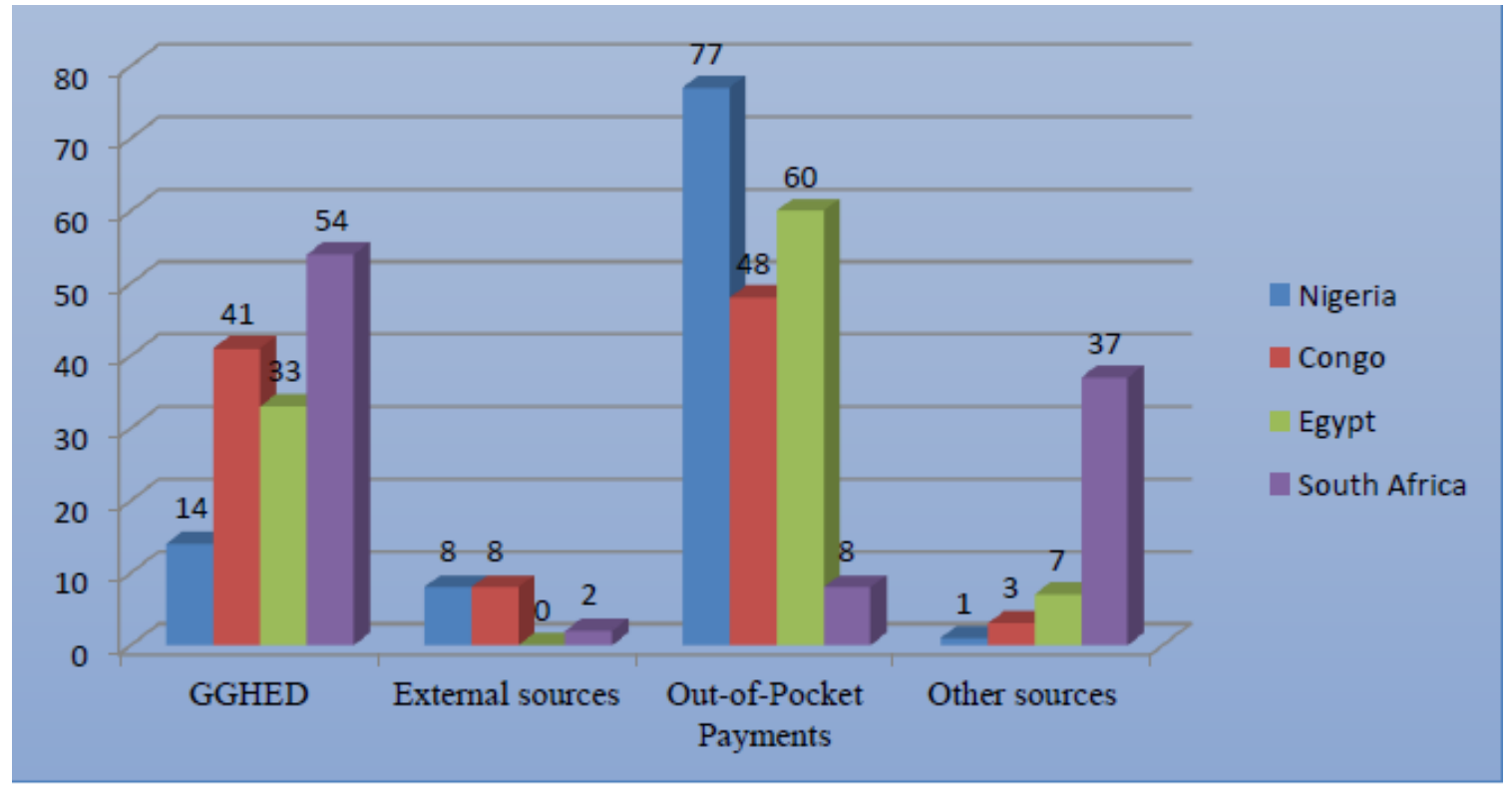

Figure 5. Mix of Healthcare Funding Sources in 2017 (\%) 


\section{Chart Key: \\ GGHED - Gross Government Health Expenditure \\ EXT - External Sources including donor funds \\ OOPS - Out-of-Pocket Payments \\ Others - Insurance, Loans, donations, missions}

\section{Healthcare Spending per Country, per Capita, and Percentage of GDP}

South Africa spends more than other African countries on healthcare per capita, averaging \$518 US since 2010. South Africa has been experiencing a decline in the amount of money spent on healthcare since 2010 up to 2017 (see figure 6). An average of $\$ 138$ US per capita was spent by Egypt between 2010 and 2017, with a peak expenditure per capita in 2015 of up to $\$ 180$ US. Nigeria's healthcare spending per capita has been dwindling with an average of $\$ 89.4$ US, with the highest healthcare spending in 2013 (\$102.5 US) and 2014 (\$107.9 US). Congo's per capita spending on healthcare between 2010 and 2017 was an average of \$62 US, with the highest per capita expenditure in 2013 amounting to \$73.4 US. Among the five African countries under consideration, Tanzania spends the least on healthcare per capita between 2010 and 2017, averaging about $\$ 36.9$ US.

\section{Healthcare Spending \% of GDP per Country in the Representing Region of Africa}

South Africa's average spending on healthcare as a percentage of GDP remains the highest in Africa, accounting for up to $7.8 \%$ of its GDP between 2010 and 2017. Tanzania spent about $4.4 \%$ of its GDP on healthcare between 2010 and 2017, while Egypt spent about 4.8\% of its GDP on average within the same year. It is noted that Tanzania's spending on healthcare appears to decline, as reflected in Figure 7, from $5.3 \%$ in 2010 and $3.6 \%$ in 2017. Nigeria spent about $3.5 \%$ of its GDP on healthcare, typical from 2010 to 2017 (Figure 7). In Tanzania, health spending trends: $9.6 \%$ of the national budget was approved in $2013 / 14 ; 9.1 \%$ in $2014 / 2015 ; 8.1 \%$ in $2015 / 2016$ and $7 \%$ in 2017/2018 (UNICEF, 2018) [13].

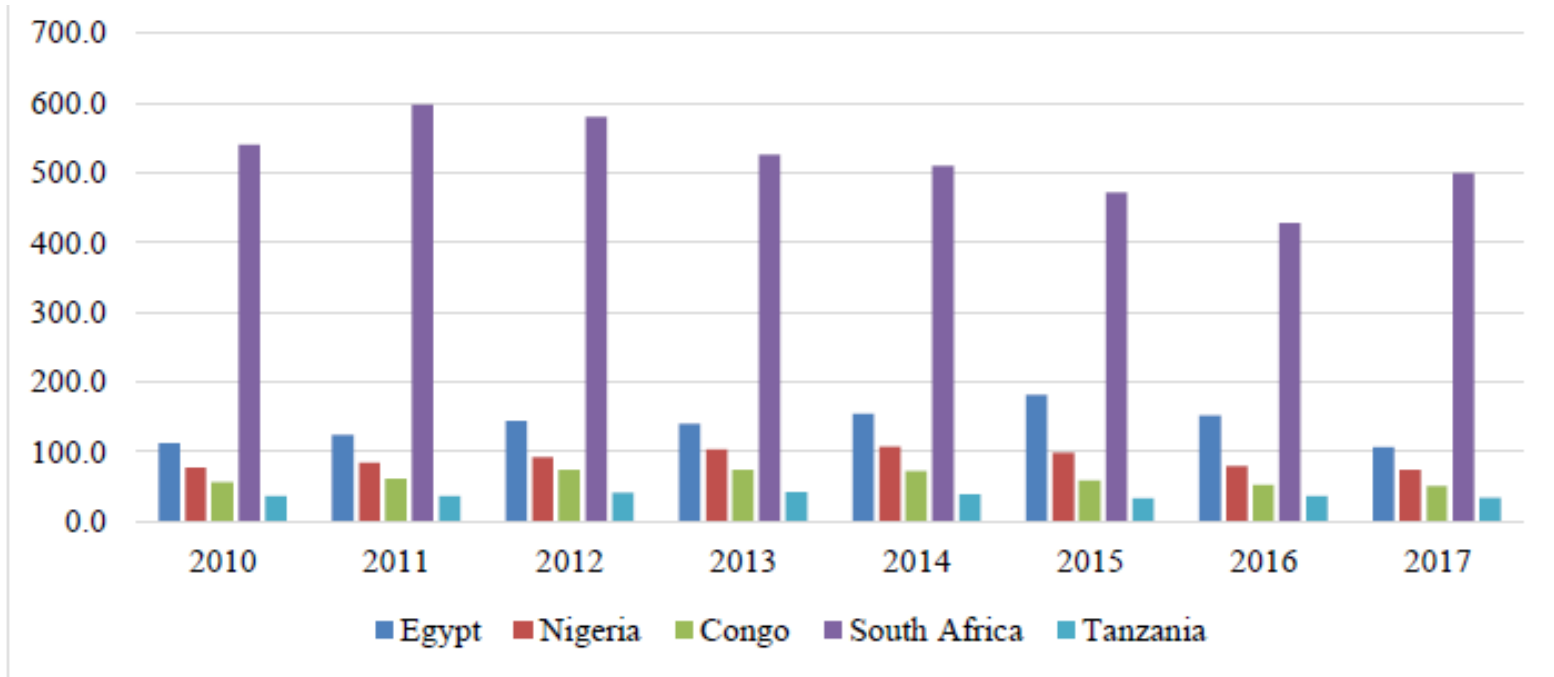

Figure 6. Healthcare Spending per capita (US \$) per County in the representing Region of Africa 


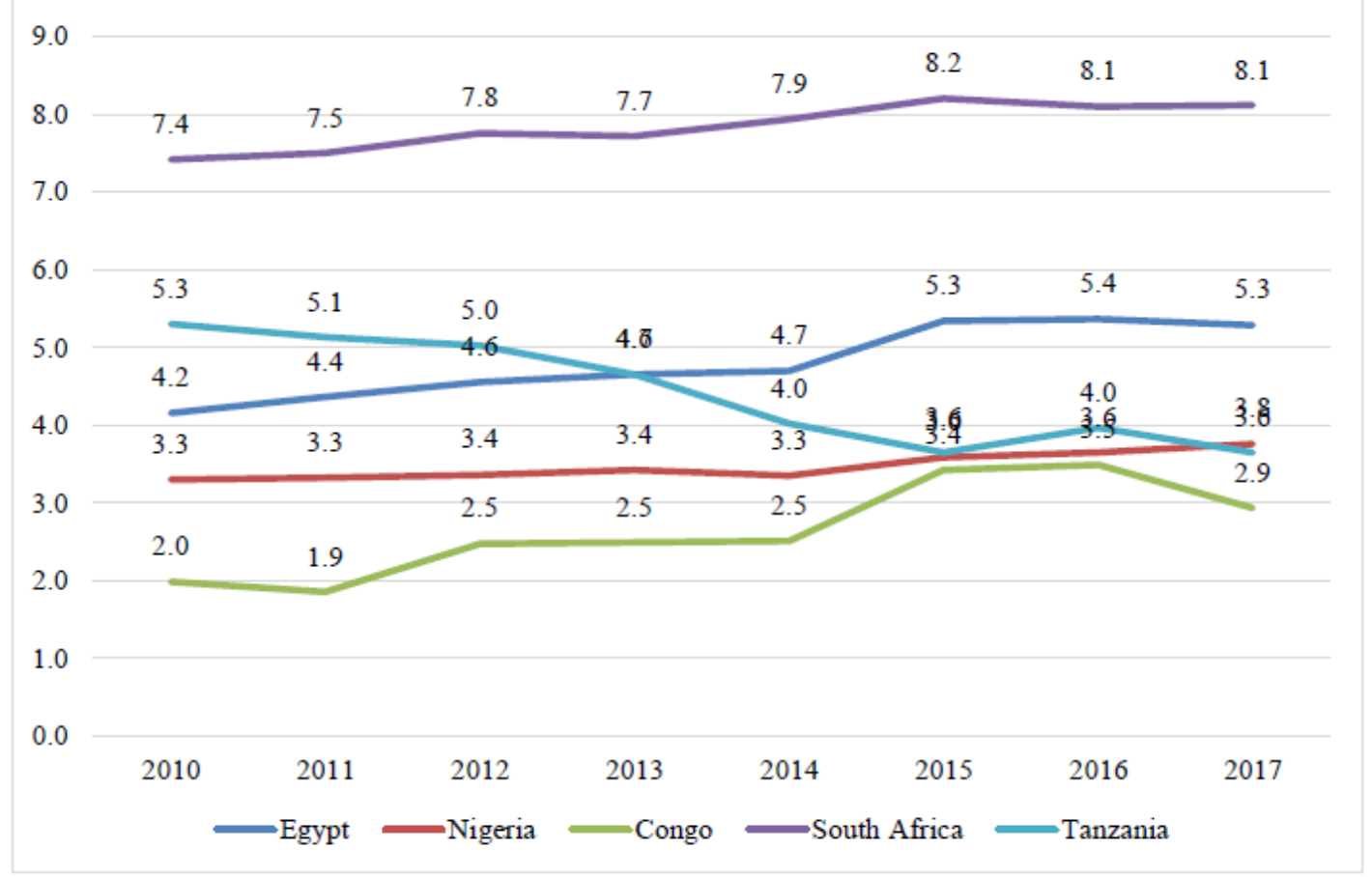

Figure 7. Healthcare spending \% of GDP per county in the representing Region of Africa

\section{Investor Opportunities that Focus on Lowering OOPs and Increasing Investor Profits to Achieve Better Health Outcomes}

\section{Evidence-based New Funding Options for Investors to Explore}

According to the IMF, as cited in a UN document on Africa renewal, between 2018 and 2023, Africa's growth prospects will be among the world's highest. A period of strong economic growth translates into the diversification of the healthcare sector in Africa. Most recently, the growing demand for healthcare (Urban and rural) requires that organizations/investors seek the most efficient way to take advantage of new technological solutions [18].

Investors need to be cognizant of the sources of healthcare funding in Africa. The findings in this study clearly show that most of the funding for healthcare in selected African countries comes from the already impoverished population's pockets. Thus, this paper attempts to present healthcare aspects with high funding potential that directly impacts the population, lowers OOPs, and increases investor profits. No doubt that investing in healthcare will make a notable economic impact in Africa. The African healthcare sector is faced with weak health systems against the backdrop of low healthcare allocations/weak commitment by the government towards the development and sustainability of the healthcare sector in Africa, mixed with multicultural and varying belief systems with a high burden of out-of-pocket expenses on health and catastrophic expenses for households. However, there is considerable demand for investment over the next decade in the health sector, such as hospital equipment, better benefits package/incentive for healthcare workers, training and capacity development, strengthening logistic management systems, monitoring and evaluation, and reporting others [19].

Also, "designing and implementing efforts to shift innovative health financing have substantial effects on the sustainability of healthcare systems" [20]. It has been identified that the gap between the demand and actual utilization of healthcare services increases healthcare systems' inequality. Subsidizing health spending could help strengthen equity while achieving the users' financial protection [20]. African nations continuously depend on 
innovative financing to achieve a more sustainable healthcare system. Hence, investors and partners need to continue moving towards pooled financing of health care services [21].

Apart from designing innovative risk pooling mechanisms, governments in certain African countries have shown interest in local pharmaceutical production, fostering technological transfer, capacity building, and improved access to essential medicines.[22] NAFDAC approved the recent "Five Plus FiveYear Validity" policy in 2019 to support the local production of essential medicines in Nigeria [22]. The European Investment Bank in December 2020 launched the first scheme to strengthen local production of active pharmaceutical ingredients in Africa and scale up drug manufacturing to improve public health in the continent [23]. Brufal and Breedon, 2017 suggested shoring up local pharmaceutical markets as a continued dependency on imported pharmaceuticals becomes logistically and economically nonviable [18]. Apart from the efforts going on in Nigeria, African governments have shown commitment to allocate resources for the development of the domestic pharmaceutical market through initiatives like Kenya Good Manufacturing Practice (GMP) roadmap; Good Manufacturing Practices for East African Community Medicines Regulatory harmonization, and the pharmaceutical markets. These initiatives are set out to align with international medicine manufacturing good practice [23].

Another promising aspect for investing in healthcare in Africa is healthcare equipment, including Personal Protective Equipment (PPEs). The COVID-19 impact on the apparel industry has pushed thousands out of jobs [24], especially in Africa. Simultaneously, the COVID-19 crisis created an opening for the garment-making industry with the rising need for personal protective equipment. A lot will go into making the much-needed PPEs such as N95 masks, medical gowns, goggles, which may entail adjusting production lines, sourcing new materials, or even obtaining a license as well as capacity building. A good example is Hela Clothing in Kenya, known for manufacturing Men's underwear that shifted to making about 10 million masks with support from IFC [24]. The International Finance Corporation (IFC) currently helps companies make medical-related materials/wears and connect them to buyers [25].

Healthcare branding dimensions, including brand elements, tangibles, personal medical quality, and critical service provision, predict healthcare brand image and return for service provision intentions among customers [26]. Hence, for African countries to engage in the profitable healthcare business, there is an ultimate need for deliberate strategic rebranding interventions in the sector. The public-private partnership might be a great instrument in achieving profitability concerning an increase in patronage.

\section{Discussions}

Egypt's health care funding as a percent of GDP and per capita improved from 2010 until 2015, when a gradual decline in budgetary allocations was observed. The budget allocation for healthcare declined from about $5.34 \%$ in 2015 to $5.29 \%$ in 2017. At the same time, the per capita allocation for healthcare expenditure declined significantly from US\$181 in 2015 to US\$106 in 2017.

Nigeria's out-of-pocket expenditure on healthcare was about $90 \%$ in 2002 and increased steadily to about $95.7 \%$ in 2012 [27]. On the other hand, the Nigerian government expenditure on health has been deficient with a weak domestic resource mobilization [28, 29]. As of 2020, Nigeria is yet to commit to the Abuja declaration in 2001 by allocating at least $15 \%$ of the budget to the healthcare system's financing despite its viable policy [30]. The NHP, 2006 was formulated to ensure that adequate and sustainable funding is available and allocated for accessible, efficient, and equitable healthcare provision and consumption [31]. In 2014 and 
2015 , the budget allocation for healthcare was 5.78 percent for each year. It was lower in 2017 with an allocation of $4 \%$ of the healthcare sector budget, which is similar to that of the year 2018 (4.4 percent) and only 4.75 percent allocated to the sector in 2019. The most recent budget for the year 2020 has a healthcare allocation of 4.14 percent, amounting to about 427.3 billion naira (Approx. USD 1.2 billion) [31].

A successful and efficient healthcare delivery system hinges on the balance that a country can achieve its current health financing needs and health expenditures [5]. Currently, Nigeria's health system is funded from budget allocations. The insurance method is risk pooling via the NHIS and its partners but mostly focuses on providing coverage for those in the formal sector. Only two countries, namely Algeria and Namibia, spend more than 5\% of GDP on health, and out-of-pocket payments are still too high [3]. Most African countries are not moving towards the African Union pledge, which they made in Nigeria in 2001 to commit at least $15 \%$ of their annual budget to healthcare. In 2011 only Tanzania had achieved the target while twentysix countries had increased the healthcare expenditure while eleven countries had reduced their budget [4].

In Africa, out-of-pocket expenditure accounts for about $36 \%$ of Africa's total healthcare spending, leading to a $\$ 66 \mathrm{bn}$ per annum financial gap [3]. Averagely, the African government spends about $7.2 \%$ of its budget on healthcare between 2000 and 2015 though with wide variations across regions. The UNECA estimated that Africa would require an accelerated economic growth from 3.2\% to double digits to achieve the SDGs. African healthcare spending is meager (only about $1 \%$ of the total global health spending as of 2015) compared to other countries globally. However, the continent bears about 23 percent of the global disease burden.

Donors in Africa often finance effective healthcare-related programs, which marked a tremendous difference in the lives and health status of most of the population they target, even though WHO data presented earlier showed that it is only a fraction compared to out-of-pocket expenditure. For instance, donors fund projects such as childhood vaccination programs and periodic campaigns, HIV, Tuberculosis, and Malaria Control [21]. Arguably, foreign aid provision to Africa by the developed countries might have contributed to Africa's stunted growth by fueling dependency syndrome and weakened administration and governance [32]. Nigeria's health care is funded from various sources and in different proportions. These sources include tax-based public sector/government allocation for healthcare, household out-of-pocket expenses, private sector/donor funding, social and communitybased health insurance, grants, and loans from donor agencies like WHO, WB, funds, and foundation [33].

In Africa, the private sector was found (in an IFC-WHO report) to be providing about half of Africa's health products and services. Hence a close partnership between the public and private sectors would lead to the apparent improvement in the healthcare sector. The public sector can provide direct guidance for the private sector's engagement while allowing flexibility and innovation to foster sustainability strategies. The private sector, especially the local and community-based organizations, can provide culturally competent healthcare services.

Seeking to bridge the funding gap in healthcare expenditure created by inadequate fund allocation for the populace's healthcare in Africa can be achieved via many interventions by actively engaging the private sector. The options for bridging the healthcare funding gap may be through the production and distribution of pharmaceuticals, health infrastructure, personnel supply, ICT development, training, and capacity building for healthcare workers [34].

According to WHO, investments in the health sector are likely to have significant benefits for both economic gains and saving lives. The 
Africa Investment Case recommends that governments and international donors' partner to improve engagement in policy dialogue among national, regional, and global stakeholders and integrate policy changes and funding changes into the national planning and budgeting process. It is important to note that investing in Africa's healthcare system is an opportunity to drive its nations' economic development and growth, which will be a significant step towards achieving the SDGs.

The Africa Investment case, an evidencebased process, and documentation provide investors with direct and clear guidance on investing in Africa's health sector. One of the main aspects of investment is the African Healthcare policy. National Health policy developed through rigorous analysis, dialogue, and evidence-based planning in better governance and accountability create a platform for sustained long-term health improvements. Measures should be put in place for intersectoral engagement targeting the social determinants of health [14]. Secondly, investors can adopt strategies that improve Africans' health by establishing mechanisms that will make purchasing health services more sustainable, create greater awareness of services

\section{References}

[1] Health Business International Conference held in London, 2018.

[2] McIntosh N., Grabowski A., Jack B., NkabaneNkholongo E. L, and Vian T. 2015, A Public-Private Partnership Improves Clinical Performance in A hospital Network in Lesotho. Health Affairs Vol 34, No 6: Variety Issue.

[3] United Nations. Economic Commission for Africa-UNECA, 2018, Economic Report on Africa 2019: fiscal policy for financing sustainable development in Africa. Addis Ababa. (C) UN. ECA. https://www.uneca.org/publications/economicreport-africa-2019 Download report here https://repository.uneca.org/bitstream/handle/10855/ 41804/b11928190.pdf? sequence $=1 \&$ is Allowed $=y$. that can be more sustainable, and better awareness of services that encourage better health-seeking behavior. Lastly, through public, private partnerships, investments in the building blocks of service provision can improve healthcare services demand. Capacity building for the workforce through sponsorships, training and re-training with better incentives can foster better healthcare service delivery.

\section{Conclusion}

In conclusion, given that providing quality healthcare service in any context comes at a cost, it would be an excellent opportunity for investors to design mechanisms for improving access to quality healthcare, locally produced standardized medicines, and locally manufactured equipment via the investorfriendly imitative highlighted. Investors and the population alike will benefit from establishing mechanisms for the modification to direct payment (OOPs) such as co-pays in insurance or establish and strengthen mechanisms that help pool risks such as voluntary or social health insurance. Exploring the option of local pharmaceutical companies may help reduce the cost burden for quality healthcare.

[4] WHO, 2011, The Abuja Declaration: Ten years on. Health systems and Innovation Publication. Retrieved on 10/2/2020 from https://www.who.int/healthsystems/publications/abu ja_declaration/en/.

[5] Olaopa, T., 2019, Health financing and the crisis of healthcare system in Nigeria. (2019, Mar 13). This Day. $\quad$ Retrieved from https://search.proquest.com/docview/2190447777?a c countid $=34773$.

[6] Tompa E., 2002, The Impact of Health on Productivity: Empirical Evidence and Policy Implications. Retrieved on 7/13/2020 from http://www.csls.ca/repsp/2/emiletompa.pdf.

[7] Youngman I., 2015, Pressure on Egypt's Ailing Health Care System. Retrieved on 10/2/2020 from 
https://www.imtj.com/news/pressure-egypts-ailinghealth-care-system/.

[8] Olasehinde, N., \& Olaniyan, O., 2017, Determinants of household health expenditure in Nigeria. International Journal of Social Economics, 44(12), 1694-1709. doi: http://dx.doi.org/10.1108/IJSE-12-2015-0324.

[9] Criel, B., Maria-Pia Waelkens, Nappa, F. K., Coppieters, Y., \& Laokri, S., 2020, Can mutual health organizations influence the quality and the affordability of healthcare provision? The case of the democratic republic of congo. PLoS One, 15(4) doi: http://dx.doi.org/10.1371/journal.pone.0231660.

[10] Vambe, A. K., 2014, An examination of health care financing models: Lessons for South Africa. Journal of Finance, Accounting, and Management, 5(1), 161-217. Retrieved on 10/2/2020 from https://search.proquest.com/docview/1506155151?a ccountid=34773.

[11] World Bank, 2019, The World Bank in South Africa: Overview. Retrieved on 10/2/2020 from https://www.worldbank.org/en/country/southafrica/o verview.

[12] WHO's MLHW Country Case Studies, Annex 5, Tanzania, Retrieved on 2/1/20 from https://www.who.int/workforcealliance/knowledge/r esources/MLHWCountryCaseStudies_annex5_Tanz ania.pdf.

[13] UNICEF, 2018, Health Budget Brief, Tanzania. Retrieved on 10/2/2020 from https://www.unicef.org/tanzania/media/1261/file/UN ICEF-Tanzania-2018-Health-Budget-Brief.pdf.

[14] WHO, 2011, Investing in Health for Africa: The Case for Strengthening Systems for Better Health outcomes. Harmonization for Health in Africa. Retrieved on 7/13/2020 from https://www.who.int/pmnch/media/membernews/20 11/investing_health_africa_eng.pdf.

[15] Baldursdóttir, S., Gunnlaugsson, G., \& Einarsdóttir, J., 2018, Donor dilemmas in a fragile state: NGO-ization of community healthcare in Guinea-Bissau, Development Studies Research, 5:sup1, S27-S39,

DOI:

10.1080/21665095.2018.1500143.

[16] WHO, 2000-2020, Health Expenditure Profile per country - Nigeria, Egypt, Tanzania, South Africa, and Congo extracted on 10/2/2020 from https://apps.who.int/nha/database/country_profile/In dex/en.

[17] Macrotrends, 2020, Healthcare Spending of various African Countries Retrieved from www.macrotrends.net,https://www.macrotrends.net/ countries/COG/congo-rep/healthcarespending? $\mathrm{q}=$ south+africa

[18] Brufal J. and Breedon R., 2017, Incentivizing the Private Healthcare Sector in Africa. Retrieved on 2/12/21 from https://gowlingwlg.com/en/insightsresources/articles/2017/incentivising-privatehealthcare-sector-in-africa/.

[19] Harmonization for Health in Africa (HHA), 2011, Investing in Health for Africa. Retrieved $10 / 2 / 2020$ from https://www.who.int/pmnch/media/membernews/20 11/investing_health_africa_eng.pdf.

[20] Dong, H., Li, Z., \& Failler, P. (2020). The impact of the business cycle on health financing: Subsidized, voluntary, and out-of-pocket health spending. International Journal of Environmental Research and Public Health, 17(6), 1928. doi: http://dx.doi.org/10.3390/ijerph17061928.

[21] Ogbuoji O., Bharali I., Emery N, and McDade K.K. (2019) Closing Africa's Health Financing Gap. Retrieved10/2/2020 from https://www.brookings.edu/blog/futuredevelopment/2019/03/01/closing-africas-healthfinancing-gap/.

[22] Fatokun, O., 2020, Fostering local production of essential medicines in Nigeria. World Health Organization.Bulletin of the World Health Organization, 98(7), 507-508. doi: http://dx.doi.org/10.2471/BLT.19.249508.

[23]EUIB: European Investment Bank launches Africa pharmaceutical manufacturing initiative. (2020, Dec 18). Targeted News Service Retrieved from

https://www.proquest.com/newspapers/europeaninvestment-bank-launchesafrica/docview/2470883941/se-2 accountid=34773. [24] Moyo M. and Lozansky T., 2020, Africa: Working with Africa's apparel makers to produce personal protective equipment. (2020, May 21). Asia News Monitor Retrieved on 10/2/2020 from 
https://www.proquest.com/newspapers/africa-

working-with-africas-apparel-

makers/docview/2404677149/se-

2 ? accountid $=34773$.

[25] International Finance Corporation, 2008, Health Care in Africa: IFC Reports see Demand for Investment. Retrieved on 8/2/2020 from https://www.ifc.org/wps/wcm/connect/news_ext_co ntent/ifc_external_corporate_site/news+and+events/ healthafricafeature Lancet. 2015; 386: 227-229.

[26] Odoom, P. T., Narteh, B., \& Odoom, R., 2019, Healthcare branding: Insights from Africa into health service customers' repeat patronage intentions, International Journal of Healthcare Management, DOI: $10.1080 / 20479700.2019 .1688503$.

[27]WHO, 2015, Global Health Observatory. Nigeria: Statistics summary $(2002-2015)$ retrieved on $8 / 12 / 2020 \quad$ from http://apps.who.int/gho/data/node.country.countryNGA.

[28] Olakunde B. O., 2012, Public health care financing in Nigeria: which way forward? Ann Nigerian Med. 2012; 6: 4-10.

[29] Yates R., 2015, Universal health coverage: progressive taxes are key. Retrieved from
https://www.thelancet.com/journals/lancet/article/PII S0140-6736(15)60868-6/fulltext.

[30] Nigeria's National Health Policy, 2006.

[31] Uzochukwu B. S. C., Ughasoro M. D., Etiaba E., Okwuosa C., Envuladu E., Onwujekwe O. E. (2015) Health care financing in Nigeria: Implications for achieving universal health coverage. Nigerian Journal of Clinical Practice, Vol 18, Iss. 4, Pg. 437 444 DOI: 10.4103/1119-3077.154196 retrieved from http://www.njcponline.com/article.asp?issn=11193077 ; year $=2015$; volume $=18 ;$ issue $=4$; spage $=437$; epa ge $=444$; aulast $=$ Uzochukwu .

[32] Park J. D., 2019, Assessing the Role of Foreign Aid, Donors, and Recipients. In: Re-Inventing Africa's Development. Palgrave Macmillan, Cham. https://doi.org/10.1007/978-3-030-03946-2_2.

[33]Eboh A., Akpata, G. A., Akintoye A. E. (2016) Health Care Financing in Nigeria: An Assessment of the National Health Insurance Scheme (NHIS) retrieved from https://iiste.org/Journals/index.php/EJBM/article/vie wFile/33191/34089.

[34] Songwe V. (2019) Financing Africa's Healthcare. GBC News. Retrieved from https://gbchealth.org/financing-africas-healthcare/. 